Revista de la red interuniversitaria de estudios sobre las literaturas rioplatenses contemporáneas en Francia

\title{
"Los restos de un futuro que vuelve" : reediciones y relecturas del pasado reciente en la crítica y la literatura argentinas contemporáneas
}

Diego Peller

\section{(2) OpenEdition}

\section{Journals}

Edición electrónica

URL: http://journals.openedition.org/lirico/2123

DOI: $10.4000 /$ lirico. 2123

ISSN: 2262-8339

Editor

Réseau interuniversitaire d'étude des littératures contemporaines du Río de la Plata

Referencia electrónica

Diego Peller, «"Los restos de un futuro que vuelve" : reediciones y relecturas del pasado reciente en la crítica y la literatura argentinas contemporáneas », Cuadernos LIRICO [En línea], 13 | 2015, Publicado el 15 diciembre 2015, consultado el 10 diciembre 2020. URL : http://journals.openedition.org/lirico/2123 ; DOI : https://doi.org/10.4000/lirico.2123

Este documento fue generado automáticamente el 10 diciembre 2020.

Cuadernos LIRICO está distribuido bajo una Licencia Creative Commons Atribución-NoComercialSinDerivar 4.0 Internacional. 


\title{
"Los restos de un futuro que vuelve": reediciones y relecturas del pasado reciente en la crítica y la literatura argentinas contemporáneas
}

\author{
Diego Peller
}

1 Entre los ejes que vienen organizando el debate crítico de los últimos años sobre literatura argentina contemporánea se encuentra, sin dudas, en un lugar central, aquel que plantea una relación más o menos inmediata entre las transformaciones sociales, políticas y económicas de la última década y su correlato en las transformaciones correspondientes en el plano de la literatura. Según los que postulan dicha inmediatez, habría una "nueva literatura argentina", que habría comenzado a emerger alrededor de la crisis del 2001 y se habría ido configurando a lo largo de la década 2004-2014, y por otra parte, resultaría de una evidencia contundente que dicha irrupción de "lo nuevo" (nuevas ficciones y nuevas estéticas, nuevos modos de constitución de las figuras de autor, editor y -agrego- de crítico) estaría en una relación directa e innegable con las intensas transformaciones políticas experimentadas por la sociedad argentina entre la década del noventa, la crisis del 2001, y los años 2004-2014 (cuya nominación es objeto de apasionados debates entre quienes ven en ellos una década "ganada" o "perdida"1). Todo esto es bien conocido, y ha llegado a constituirse acaso en un lugar común de la crítica, casi una obviedad, lo que no le resta nada de su fuerza. En 2003, dentro de un volumen colectivo titulado Imágenes de los noventa, Tomás Abraham comenzaba su colaboración señalando "La década del noventa efectivamente constituye una década" (101). Eso, que podía parecer una obviedad o una tautología, aclaraba Abraham, no lo era, porque hay supuestas "décadas" que se desdibujan en cuanto uno pretende adosarles un significado unívoco o colocarles marcaciones temporales precisas. Pero sin dudas no pasaba eso con los años noventa, dado que fechas como 1989, con la caída del Muro de Berlín y con el fin anticipado del gobierno de Alfonsín, y 2001, con el ataque a las Torres Gemelas en septiembre y con la crisis de diciembre en Argentina, acompañadas de significantes como 
"menemismo" o "neoliberalismo", poseían la suficiente eficacia simbólica para delimitar la década con precisión. Me permito recordarlo porque entiendo que denominaciones como "literatura de los 90", "literatura del kirchnerismo", o "década kirchnerista" se presentan hoy ante nosotros con el mismo efecto de inteligibilidad inmediata.

2 Al mismo tiempo, resulta importante señalar, en estas "nuevas periodizaciones", o en estas periodizaciones de "lo nuevo", la persistencia conceptual de tres patrones que las ligan con criterios de periodización clásicos que nos retrotraen, al menos, hasta la segunda mitad del siglo veinte, introduciendo así una temporalidad más compleja que en cierta medida pone en cuestión el presentismo imperante en algunos sectores de la crítica actual.

3 La primera de estas tres constantes es el recurso a la década como categoría de periodización, articulada con la generación como categoría analítica. La segunda constante, que se articula con la anterior, es la referencia a "grandes acontecimientos" de la historia política que operan como parteaguas que delimitan con supuesta contundencia esas "décadas" en las que parece dividirse con naturalidad nuestra historia reciente. En algunos casos, la Historia parecería haber provisto al historiador con acontecimientos lo suficientemente notables como para evitar toda querella en relación a estas demarcaciones, y entonces 1945, 1955, 1976, 1983, 1989, 2001 serían fechas-clave dotadas de la suficiente elocuencia para ahorrarnos todo comentario. En otros casos no ha sido así, como si la Historia, perezosa, no hubiera llegado a desplegar el necesario dramatismo, y ello ha suscitado prolongados debates entre los especialistas. Es el caso, por ejemplo, de la delimitación interna dentro del período 1955-1976. Nadie parece dispuesto a poner en duda la cohesión interna de estos veinte años, recortados entre la "Revolución Libertadora" y el "Proceso", para constituirse como un período histórico definido. Pero, ¿hay que hablar de los "sesenta-setenta" como un todo? Esa es la posición de Claudia Gilman, quien declina establecer una distinción significativa entre ambas décadas, refiriéndose a "los años sesenta/setenta" (13) o a "los "largos sesenta" (39). ${ }^{2}$ Otros autores, por el contrario, han sostenido la necesidad de distinguir entre década del sesenta y del setenta y no han faltado acalorados debates acerca del punto preciso en que habría que situar dicho límite. ${ }^{3}$

La tercera constante, que termina de dar forma al modelo analítico que procuro caracterizar, es la afirmación sostenida de una relación directa entre la literatura argentina y su "realidad política", para decirlo con los términos acuñados por David Viñas en su clásico Literatura argentina y realidad política (1964). Pero la afirmación de una determinación de las producciones culturales por la política no se agota en Viñas. Décadas después, Oscar Terán (1993), al justificar su uso de acontecimientos políticos como mojones temporales privilegiados en su influyente estudio sobre la formación de la nueva izquierda intelectual argentina, acuñó otra expresión que habría de tener un profuso impacto entre los historiadores de la cultura, según la cual si la periodización cultural por él propuesta (1955-1966) enfatizaba "el peso de los fenómenos políticos por sobre el de otras series de la realidad", no hacía con ello "más que traducir lo que fue una convicción creciente pero problemática del período: que la política se tornaba en la región dadora de sentido de las diversas prácticas [...]" (12). Esa convicción, como era previsible, siguió guiando los trabajos de historia de la literatura argentina producidos bajo la tutela de Viñas, como es el caso de su ambicioso proyecto de una Historia social de la literatura argentina, de la cual solo se publicó originalmente un primer tomo, Yrigoyen entre Borges y Arlt 1916-1930 (1989), bajo la dirección de Graciela Montaldo, y que luego se 
retomó, con modificaciones, en los últimos años. ${ }^{4}$ Pero también se encontraría operando, solapadamente, en un proyecto historiográfico que, en principio, se presenta en las antípodas del de Viñas, como es el caso de la Historia crítica de la literatura argentina dirigida por Noé Jitrik, antiguo compañero de Viñas en Contorno, cuyo primer tomo se publicó bajo la dirección de Susana Cella en 1999. ${ }^{5}$

El modelo analítico caracterizado por la conjunción de estas tres constantes (periodización por décadas, utilización de grandes acontecimientos históricos para jalonar dicha periodización, afirmación de una determinación directa de la serie literaria y cultural por la realidad política) termina de consolidarse cuando da un rápido desliz desde una caracterización descriptiva (según la cual existe una "literatura de los 90" que "responde a" o "refleja" ciertas coordenadas históricas -"menemismo", "neoliberalismo"- así como existe una "literatura del 2004-2014" que "responde a" o "refleja" otras determinaciones históricas -kirchnerismo-) hacia una caracterización valorativa y prescriptiva (según la cual habría ciertos rasgos formales o temáticos que resultarían "necesarios", "aceptables" en la literatura de los 90 -porque responderían a su coyuntura histórica- pero que se tornarían reaccionarios, inadmisibles en una coyuntura tan diferente como lo es la de la década 2004-2014). Se trata de un modelo teórico deudor de Lukács, si pensamos por ejemplo en el modo en que el marxista húngaro afirmaba, en su ensayo "El Hyperion de Hölderlin" que, mientras el lamento elegíaco por la imposibilidad de un retorno al helenismo en Hyperion resultaba no solo comprensible en términos históricos sino que expresaba el máximo grado de conciencia política revolucionaria que podía llegar a formularse en la atrasada Alemania de fines del siglo XVIII, una obra literaria que repitiera ese mismo lamento en una situación por completo diferente (e históricamente más "avanzada") como la de Inglaterra a comienzos del XIX no podía sino expresar una ideología reaccionaria con respecto a las transformaciones sociales de su tiempo. La prueba más contundente de eso era para Lukács la existencia de un poeta como Shelley: "Con Shelley se abre la perspectiva de la transición de los jacobinos nacidos demasiado tarde para su propia clase : ahora pueden pasar a la real lucha liberadora de la humanidad". Así, "Un Hölderlin posterior [a su época] que no hubiera emprendido el camino de Shelley no habría sido ya ningún Hölderlin, sino un mediocre liberal clasicista", una crítica que se aplica a "todos los que han repetido el lamento de Hölderlin una vez superado por la historia el fundamento que lo desencadenó, la desesperación objetiva de su situación" (Lukács 235).

6 Un ejemplo de este salto hacia la valoración prescriptiva en la crítica argentina reciente lo constituye la reseña de Violeta Kesselman (2013a) del libro de Mariana Eva Pérez Diario de una princesa montonera (2012). El Diario reúne muchos de los rasgos que definen a la "nueva literatura argentina" : tiene su origen en un blog y solo posteriormente se publicó como libro; se instala con comodidad en el territorio ambiguo entre ficción y testimonio propio del "giro autobiográfico" (Giordano 2007, 2008, 2011) o "subjetivo" (Sarlo 2005) que caracteriza a todo un sector de la producción literaria argentina reciente. La reseñista también integra una línea destacada dentro de esta nueva literatura, la que podríamos agrupar en torno a la publicación digital Planta (para una atenta caracterización de Planta, y de otras revistas recientes en formato virtual cf. Djament 2013) y a su continuación en la revista Mancilla ; coeditó, junto con Ana Mazzoni y Damián Selci, una Antología crítica de la poesía de los 90 sobre la que volveremos más adelante y publicó, en 2013, el volumen de cuentos Intercambio sobre una organización, en la editorial independiente Blatt \& Ríos. 
7 En su lectura, el énfasis está puesto en aquello que el Diario introduce de nuevo con respecto a otras obras de testimonio-ficción sobre la última dictadura producidas por la generación de los "hijos" durante la década del noventa, o con posterioridad a dicha década pero utilizando recursos propios de ésta. "Diario de una princesa montonera introduce una variación imprescindible en la narrativa alrededor de la última dictadura y sus efectos en el presente" (Kesselman). La innovación señalada es temática : mientras en los relatos del Félix Bruzzone de 76 o Los topos o en el biodrama Mi vida después, de Lola Arias, las acciones se mantienen "dentro del círculo familiar", la familia es "la protagonista exclusiva" y todo sucede dentro de un espacio "donde prácticamente no hay reconocimiento de la mediación del Estado y las organizaciones de derechos humanos" ( Ibíd.), en la narración de Pérez "ingresan al texto otros personajes, es decir, otros actores sociales: el Estado en sus distintos niveles, organizaciones de peso político, organizaciones pequeñas, militantes por los derechos humanos, ex militantes de los setenta, testigos de los juicios por los crímenes de lesa humanidad, doctorandos, universidades extranjeras" (Ibíd.). Estas "determinaciones materiales", aunque resultaban ya "evidentes para la mayoría de los habitantes de la Argentina", hasta ahora "no habían sido incorporadas de ese modo por otros autores" (Ibíd.). Lo que podía resultar aceptable o, en los términos fuertes de Lukács, históricamente verdadero- en la narrativa de los noventa (aislamiento del sujeto, repliegue sobre lo familiar-privado, desesperanza, despolitización, ironía, desencanto, minimalismo narrativo) se vuelve, frente a las transformaciones experimentadas en el plano de la "realidad política" ("evidentes para la mayoría de los habitantes") inaceptable, mera repetición formalista y por ende políticamente reaccionario e históricamente falso. Al no sincronizarse con su presente político, autores como Bruzzone y Arias estarían produciendo una ficción que no "da cuenta" de las transformaciones de su época, una literatura que atrasa. Frente a ellos, el libro de Pérez señala el camino a seguir : "Más allá de sus limitaciones estilísticas, e incluso de las opiniones críticas de la autora sobre la política de derechos humanos de los últimos años, Diario... redefine el piso para la literatura sobre el Proceso. La narración abandona un estado de cosas y de ánimo detenido en los noventa y se sitúa en 2013" (Ibíd. ) .

8 Idéntico argumento presenta el ensayo "El tópico del trabajo y el mínimo de subjetividad”, publicado conjuntamente por Ana Mazzoni, Damián Selci, Nicolás Vilela y Violeta Kesselman en el número 9 de la revista Planta :

Los años 90 fueron prolíficos en novelas y cuentos por cuyas páginas vagabundeaban, semimuertos, personajes desinteresados, irreflexivos, apáticos, eventualmente consumistas, fiesteros o drogones en público y abúlicos perplejos en privado. Las narraciones de Martín Rejtman, pese a que no ocuparon un lugar central, sintetizan este recorrido. De un tiempo a esta parte, la situación política y cultural, los presupuestos productivos y los pactos de lectura se modificaron, pero las subjetividades narrativas no parecieron acompañarlos (citado en Djament 2013, énfasis mío).

9 Nuevamente, lo que se le reclama a la literatura es que se ajuste a su "realidad", "como si a un determinado momento político le correspondiera en términos de expresión una determinada narrativa" (Djament). Y es justamente por esa sincronía con su tiempo que, en su antología crítica La tendencia materialista, Kesselman, Mazzoni y Selci (2012) valoran positivamente a un determinado segmento dentro de la poesía argentina de los años noventa: se trata de textos que "fueron acontecimientos que se enclavaron profundamente en la época y de alguna manera permitieron comprenderla" (5), 
trascendiendo incluso el modesto campo de la literatura : "la importancia de la poesía de los 90 no depende solamente de que pueda medirse con los más altos estándares de la literatura argentina. Hay otra razón : en ella se encuentran percepciones muy agudas de la historia reciente" (5), gracias a las cuales "buena parte de la poesía de los 90 trasciende, por su capacidad para articular problemáticas de largo alcance, las cuestiones estrictamente literarias" (6).

La antología presenta dos grandes objetivos declarados : el primero es ampliar el círculo de lectores para un conjunto de obras y de poetas que consideran -con toda razón- muy valiosos pero que, más allá de su intensa circulación dentro del ámbito restringido de los cultores fervorosos de la poesía, había sido muy poco leída. Los poemas seleccionados habían sido publicados previamente en editoriales pequeñas y de tiradas reducidas; la operación fundamental en ese sentido es seleccionar a un acotado conjunto de autores dentro del amplio espectro de "poetas de los noventa", y publicar sus poemas en una editorial de mayor circulación como Paradiso. El segundo objetivo es ofrecer, acompañando la selección, un esquema analítico fuerte, que dé inteligibilidad al conjunto. Para lograrlo la antología está organizada en tres núcleos, "La percepción cultural", "La percepción política" y "Percepción histórico-económica" ; al primer núcleo corresponden los poemas de Juan Desiderio, Fabián Casas, Fernanda Laguna ; al segundo, los de Martín Gambarotta, Washington Cucurto, Alejandro Rubio ; al tercero, los de Sergio Raimondi. Esta tríada de "percepciones", aunque pueda haber por momentos solapamientos o mixturas, no establece una relación de simultaneidad, sino de evolución: la percepción política "supera", en sentido hegeliano (y Hegel no casualmente es invocado en la introducción), a la cultural ; mientras la histórico-económica implica una instancia de superación respecto a las otras dos. Esta evolución lógico temporal de una percepción a la siguiente, es señalada por los propios autores: "Esta ordenación lógica coincide casi perfectamente con la ordenación cronológica (la única excepción sería Fernanda Laguna [señalo : la única mujer seleccionada en la antología es quien viene a desordenar el "casi perfecto" esquema lógico-temporal]), lo que sugiere que, al interior de la tendencia materialista de la poesía de los 90, ciertos problemas poéticos sólo pueden plantearse cuando se han resuelto otros" (9). Esta lógica totalizadora de matriz hegeliana que ordena el material fue destacada también, como un rasgo supuestamente positivo de la antología, por Nicolás Vilela, en un texto leído en la presentación del libro en el Museo del Libro y de la Lengua, y luego publicado en la revista Mancilla :

Por cómo está organizado el material y por la propia cronología de las publicaciones, el armado del libro es una especie de fenomenología del espíritu en la que cada instancia lleva a la siguiente y finalmente todo se sintetiza en una totalidad. Parece una historia de la conciencia literaria de la poesía de los 90 (109).

11 Al mismo tiempo, Vilela también insiste en otro rasgo que hemos señalado previamente como característico de esta concepción de la relación entre literatura y sociedad : la idea de una posible -y valorada- adecuación inmediata de la poesía a su realidad circundante : "Los temas, los problemas sociales que recorren estos poemas son de una actualidad absoluta en el sentido de que nos son contemporáneos [...]. Son temas que a un lector no especializado en poesía, siquiera en literatura, le remiten directamente a nuestro presente" (108).

Me he detenido en los presupuestos teóricos en que se sostiene esta antología porque entiendo que es representativa de una línea importante dentro de la literatura y la crítica contemporáneas en Argentina. Sin embargo, acompañando y complicando esta 
concepción lineal evolutiva de la relación entre la literatura y su presente, es posible oír, como en sordina, voces que introducen temporalidades más complejas y enrevesadas dentro del campo literario y editorial contemporáneo, por ejemplo, en el modo en que algunas de las llamadas editoriales pequeñas o independientes han acompañado su apuesta sostenida por publicar novedades en el terreno de la ficción y el ensayo con una no menos sostenida apuesta por la reedición de algunos autores fundamentales para pensar el mapa de las últimas décadas. No se ha tratado, en estos casos, de reediciones convencionales, mera reposición de títulos faltantes en el mercado, sino de verdaderas políticas de reedición, entendidas como intervenciones activas, estratégicas, sobre el presente de la literatura argentina. El fenómeno resulta particularmente notable en las reediciones de algunos textos clave de las décadas del sesenta y del setenta en Argentina, un período histórico que continúa generando intensos debates en la narrativa y el ensayo contemporáneos. Nuevamente, encontramos aquí la comodidad de la división en décadas, en generaciones, y su correlato material casi obligado: las revistas culturales. Tendríamos, por un lado, a la "generación Contorno", agrupada en torno a la revista homónima, publicada en Argentina entre 1953 y 1959, pero considerada un caso emblemático de la modernización de la crítica (y de la cultura argentina en su conjunto) que habría tenido lugar en la década del 60. Y tendríamos, por otra parte, a la generación siguiente, marcada por la publicación de dos revistas emblemáticas de los setenta, Los Libros (1969-1975) y Literal (1973-1977). No constituye un hecho azaroso, en este sentido, que la Biblioteca Nacional, que comenzó a desarrollar una novedosa política editorial a partir del año 2005, al asumir su dirección el sociólogo y ensayista Horacio González, haya inaugurado su colección Reediciones y Antologías en 2007 con la publicación de la edición facsimilar de Contorno, a la que le siguieron, entre otras reediciones, las de las Literal y Los Libros en 2011. Tampoco parece producto del azar que esta política de reediciones se haya visto acompañada por otra, que en una primera lectura parecería ir en una dirección por completo diferente, de relanzamiento de la revista La Biblioteca, una publicación de periodicidad anual con una clara impronta de intervención ensayística sobre el presente ${ }^{6}$. Podría pensárselo como un gesto doble, un doble objetivo, pero me parece más preciso ver allí un objetivo único que se jugaría siempre y necesariamente en dos tiempos, dos frentes, dos tableros ; un gesto intempestivo que buscara ligar en un instante imposible en términos de Jacques Derrida- lo hiperactual con lo anacrónico ${ }^{7}$ : por un lado, una voluntad de intervención "directa" en el presente ( $\mathrm{La}$ Biblioteca), por el otro la recuperación selectiva de algunos textos y nombres del pasado a los que se les reconoce (o de los que se presupone o se espera) una capacidad singular para "interpelarnos en nuestra existencia común" y así hacernos "repensar nuestra incierta experiencia contemporánea", según palabras de González al presentar la colección". Un índice elocuente de la voluntad de ligar estas reediciones al presente, y no pensarlas como mera reposición de material de archivo, radica en la decisión de acompañarlas por introducciones escritas por autores jóvenes no vinculados por su experiencia directa a la historia de estas revistas. Así, mientras en el caso de la reedición de Contorno -el que inaugura la colección- el gesto aún es más clásico y la edición facsimilar viene precedida entonces por dos introducciones, una de González (en su rol de Director) y otra de Ismael Viñas (en tanto protagonista directo), ya en el caso de las reediciones de Los Libros y de Literal nos encontramos con que vienen precedidas por trabajos de jóvenes investigadores sin vinculación con la época de publicación original. setenta no es patrimonio exclusivo de la Biblioteca Nacional. Unos años antes, Santiago 
Arcos, entonces una recién surgida editorial independiente, inauguraba su catálogo en 2002 publicando, simultáneamente, dos libros de ficción (Aventuras de un novelista atonal, de Alberto Laiseca y Los sospechados, de Milita Molina) junto a la primera antología de la revista Literal (compilada y prologada por Héctor Libertella), a los que se sumaría en 2003 la reedición de Indios, ejército y frontera, de David Viñas, cuya primera edición, de 1982, resultaba inhallable hacía tiempo. Pronto volveremos sobre el interés sostenido de Santiago Arcos Editor por la obra ensayística de David Viñas (en 2005 publican una nueva edición de su clásico Literatura argentina y política, en dos tomos -De los jacobinos porteños a la bohemia anarquista y De Lugones a Walsh- mientras que en 2013 lanzan su Biblioteca David Viñas, con una nueva reedición de Indios, ejército... a la que se suma en 2014 la reedición de De los montoneros a los anarquistas (1971) y cuyo plan incluye la publicación futura de otros cuatro títulos : una edición crítico genética de Literatura argentina y política ; México y Cortés ; Artículos críticos y Mansilla : entre Rosas y París). En todo caso, lo que me interesa señalar en este punto es que algunas de las nuevas editoriales independientes surgidas en los últimos años en la Argentina (aunque no todas), exhiben como uno de sus rasgos distintivos, característicos, una sostenida voluntad "anacrónica" de reeditar algunos textos y autores clave del pasado reciente. De hecho, quizás sea esta una forma posible, entre otras, de arriesgar una clasificación dentro del conjunto de estas nuevas editoriales independientes: distinguiendo entre aquellas que entienden que su intervención sobre la actualidad pasa exclusivamente por la publicación de "lo nuevo" en el sentido común del término, y aquellas otras que, en formas y grados diversos, comparten la convicción de que al menos una parte de su intervención sobre el presente pasa por la reedición de textos de hace unas décadas, o por el rescate de textos nunca publicados de autores de esos años. Son muchos los ejemplos que podrían darse, pero antes de avanzar con el listado de editoriales, títulos y nombres propios, querría introducir otros dos criterios distintivos que podrían ser útiles a la hora de encarar, en un trabajo futuro, un estudio pormenorizado del modo en que se organizan estas políticas de reedición en el campo cultural argentino de los últimos años. La primera distinción es entre aquellas editoriales que presentan claramente un plan o programa de reedición de un conjunto significativo de títulos de un mismo autor, constituyendo así, explícita o implícitamente, una "biblioteca". La segunda distinción es entre las reediciones que buscan atenuar, disimular o directamente borrar las marcas de su carácter de tales y aquellas otras que, por el contrario, desde instancias paratextuales como la contratapa, la solapa, y especialmente el prólogo, remarcan -y reflexionan sobre- el necesario desfasaje con el "original", ese juego de iteración y différance que caracteriza a toda reedición. Estos rasgos opositivos (editoriales que reeditan / editoriales que no reeditan; reediciones que forman colecciones / reediciones erráticas; reediciones "explícitas" / reediciones "disimuladas") nos pueden ayudar a discernir entre aquellas políticas de reedición con un mayor grado de autoconciencia, pensadas como verdaderas intervenciones en sentido fuerte sobre el presente, y aquellas otras más esporádicas, impulsadas quizás por la mera intención de reponer un título faltante o seguir los vaivenes de las modas editoriales.

Un estudio pormenorizado de las políticas de reedición recientes, según los criterios antes esbozados permitiría caracterizar con mayor precisión las diferentes reediciones de autores como Osvaldo Lamborghini, Héctor Libertella, Néstor Sánchez, Leónidas Lamborghini, Josefina Ludmer, Néstor Perlongher y, retrocediendo de los setenta a los sesenta, Oscar Masotta, Carlos Correas y David Viñas. Tomemos, a título exploratorio, el caso de este último. La reedición de un amplio sector de su obra ensayística por Santiago Arcos Editor constituye un caso ejemplar de reedición planificada como intervención 
sobre el presente ${ }^{9}$ : no solo se reedita un conjunto de textos del mismo autor, sino que se los acompaña de prólogos que reflexionan sobre esa intervención (de Horacio González a la reedición de Indios, ejército y fronteras; de Javier Trímboli a la reedición de De los montoneros a los anarquistas) e incluso de una breve nota escrita por el propio Viñas en 2007, cuando comenzó a planificarse la publicación de De los montoneros..., en la que introduce un provocativo comentario : "Al reeditar este trabajo intento recuperar un par de cosas : en primer lugar, que los planteos generales de 1971 se encuentran vigentes. He resuelto, por lo tanto, no modificar ni una línea" (Viñas 2014 17). Si tenemos en cuenta los sucesivos reproches de los que la obra crítica de Viñas ha sido objeto, especialmente por parte de la revista Punto de Vista, pero también en el ya mencionado artículo de Schvartzman, en el sentido de cierto anacronismo de su perspectiva, es posible apreciar hasta qué punto la declaración de Viñas constituye una provocación. En ese sentido, la repetición de lo mismo, sin modificar "ni una línea", puede adquirir -es lo que parecen entender Viñas, Trímboli y Santiago Arcos- el valor de una novedad en el contexto contemporáneo: se nos presenta así como "los restos de un futuro que vuelve", según palabras de Libertella (2002 5). Claro que para que ese insistente retorno de lo mismo sea legible como tal -y conserve así su fuerza disruptiva- requiere de la breve nota que lo acompaña, añadiéndose, como suplemento, al texto "original". Pero no siempre ocurre así. Consideremos, por ejemplo, las reediciones de La Operación Masotta (1991) de Carlos Correas y de Hombres de a caballo (1967) de Viñas, ambas publicadas en 2005 por Interzona : no hay ningún comentario o indicación en estos libros (ni en la contratapa, ni en la solapa, ni en ningún añadido textual) que señale que se trata de reediciones ni que formule alguna reflexión al respecto. Todo ocurre como si, seguramente otra vez desde una concepción ingenua de lo que se entiende como "novedad" y como intervención sobre el "presente", se estuviera procurando borrar las marcas del carácter "inactual" de estas ediciones, como si se tratara de un demérito, sin advertir que de ese modo estas pierden gran parte de su potencial intempestivo. Podemos ver entonces cómo una misma concepción simplista de "lo nuevo", entendido como actualidad sin matices, enlaza estas políticas de reedición, que hacen del borrado de las huellas del pasado su marca paradójica, con los presupuestos teóricos que, como ya señalamos, subyacen a la antología y a los artículos críticos previamente estudiados. Y cómo a esta concepción de lo actual se le contrapone otra, que hemos caracterizado como intempestiva y anacrónica, que entiende el presente como un campo heterogéneo, siempre asediado por los espectros activos de un pasado que vuelve.

\section{BIBLIOGRAFÍA}

\section{Bibiografía}

Abraham, Tomás. "Polo en la década del '90”. Imágenes de los noventa, ed. Alejandra Birgin y Javier Trímboli. Buenos Aires : Libros del Zorzal, 2003. 99-123.

Correas, Carlos. La operación Masotta. Cuando la muerte también fracasa. 1991. Buenos Aires : Interzona, 2005. 
Derrida, Jacques. “Entrevista : Deconstruir la realidad”, El ojo mocho 5 (1994) : 12-24.

Djament, Leonora. "Las vueltas de la teoría. Teoría y crítica literaria a comienzos del nuevo siglo”. Blog de Eterna Cadencia [en línea]. Puesto en línea el 6 de febrero de 2013. Consultado el 20 de febrero de 2015. http://blog.eternacadencia.com.ar/archives/27341

Gilman, Claudia. Entre la pluma y el fusil. Debates y dilemas del escritor revolucionario en América Latina . Buenos Aires : Siglo XXI, 2003.

Giordano, Alberto. "Cultura de la intimidad y giro autobiográfico en la literatura argentina actual", Pensamiento de los Confines, 21 (2007) : 157-167.

Giordano, Alberto. El giro autobiográfico de la literatura argentina actual. Buenos Aires : Mansalva, 2008.

Giordano, Alberto. Vida y obra : otra vuelta al giro autobiográfico. Rosario : Beatriz Viterbo, 2011.

Jitrik, Noé, director. Historia crítica de la literatura argentina. Volumen 10. La irrupción de la crítica. Susana Cella, editora. Buenos Aires : Emecé, 1999.

Kesselman, Violeta, Ana Mazzoni y Damián Selci (compiladores). La tendencia materialista. Antología crítica de la poesía de los 90. Buenos Aires : Paradiso, 2012.

Kesselman, Violeta. "Diario de una princesa montonera, de Mariana Eva Pérez", Otra Parte Semanal [en línea]. Puesto en línea el 11 de abril de 2013. Consultado el 20 de febrero de 2015. http:// revistaotraparte.com/semanal/discusion/diario-de-una-princesa-montonera/

Libertella, Héctor, editor. Literal 1973-1977. Buenos Aires : Santiago Arcos, 2002.

Lukács, Georg. “El Hyperion de Hölderlin”. 1934. Goethe y su época. Barcelona : Grijalbo, 1968. 213-238.

Panesi, Jorge. "La seducción de los relatos : diez años de crítica argentina (2004-2014)". Actas V Congreso Internacional de Literatura CELEHIS, Mar del Plata, noviembre 2014 (en preparación).

Panesi, Jorge. “Pasiones de la historia”. Filología XXXII 1-2 (1999) : 121-128.

Panesi, Jorge. “Un lugar donde la crítica rinde examen”. Espacios de crítica y producción 26 (2000) : 121-125.

Pérez, Mariana Eva. Diario de una princesa montonera. Buenos Aires : Capital Intelectual, 2012.

Podlubne, Judith. "Beatriz Sarlo/Horacio González : perspectivas de la crítica cultural”. Alberto Giordano y María Celia Vázquez (compiladores). Las operaciones de la crítica. Rosario, Beatriz Viterbo, 1998. 67-77.

Sarlo, Beatriz. Tiempo pasado. Cultura de la memoria y giro subjetivo. Una discusión. Buenos Aires : Siglo XXI, 2005.

Schvartzman, Julio. (1999). "David Viñas : La crítica como epopeya”. Historia crítica de la literatura argentina. Noé Jitrik, director. Volumen 10. La irrupción de la crítica. Susana Cella, editora. Buenos Aires : Emecé, 1999. 147-180.

Sigal, Silvia, y Oscar Terán. "Los intelectuales frente a la política. Diálogo sobre sus respectivos libros sobre los años sesenta". Punto de Vista XV 42 (1992) : 42-48.

Sigal, Silvia. Intelectuales y poder en Argentina. La década del sesenta. 1991. Buenos Aires : Siglo XXI, 2002.

Terán, Oscar. Nuestros años sesentas. La formación de la nueva izquierda intelectual argentina 1955-1966. 1991. Buenos Aires : El cielo por asalto, 1993. 
Vilela, Nicolás. “La tendencia”, Mancilla 4 (2012) : 106-111.

Viñas, David. De los montoneros a los anarquistas. 1971. Buenos Aires : Santiago Arcos editor, 2014.

Viñas, David, director. Historia social de la literatura argentina. Tomo VII. Montaldo, Graciela y colaboradores. Yrigoyen, entre Borges y Arlt 1916-1930. Buenos Aires : Contrapunto, 1989.

Viñas, David. Indios, ejército y frontera. 1982. Buenos Aires : Santiago Arcos editor, 2003.

Viñas, David. Literatura argentina y realidad política. Buenos Aires : Jorge Álvarez, 1964.

Viñas, David. Hombres de a caballo. 1967. Buenos Aires : Interzona, 2005.

\section{NOTAS}

1. Estos debates han sido recientemente analizados, con sutil ironía, por Jorge Panesi (2014).

2. "Lo cierto es que la distinción entre los sesenta y los setenta carece de sentido si pensamos en que todo el período es atravesado por una misma problemática : la valorización de la política y la expectativa revolucionaria" (Gilman 38).

3. Me refiero al intercambio que tuvo lugar entre Silvia Sigal y Oscar Terán con motivo de la publicación simultánea de sus respectivos estudios sobre los años sesenta: Intelectuales y poder en Argentina (Sigal 1991) y Nuestros años sesenta (Terán 1991). Durante el diálogo, publicado poco después en Punto de Vista 42 (1992), Terán se inclinaba por poner punto final en 1966 al período que se iniciaba en 1955 con la caída de Perón, argumentando que el paso de la modernización cultural de los sesenta a la radicalización política de los setenta se debía fundamentalmente a la irrupción en el campo intelectual de presiones exógenas (a las que él denominaba "bloqueo tradicionalista") cuyo máxima manifestación era, precisamente, el golpe de Onganía en 1966 ; mientras Sigal sostenía la conveniencia de situar el punto de quiebre unos años después, ya que desde su perspectiva el paso de la modernización a la radicalización se debía a transformaciones inherentes al campo intelectual, relativamente autónomo frente a las presiones de la política.

4. En 2006 Paradiso Ediciones relanzó, modificando el título (Literatura Argentina Siglo XX, en lugar del hauseriano Historia Social de la Literatura Argentina; así como en las últimas ediciones de Literatura argentina y realidad política se ha eliminado el término "realidad") el proyecto original de Viñas, comenzando con la reedición de Yrigoyen entre Borges y Arlt (2006) y continuando con otros tomos de la colección : La década infame y los escritores suicidas (1930-1943) (2007) ; El peronismo clásico (1945-1955). Descamisados, gorilas y contreras (2007); De Alfonsín al menemato (1983-2001) (2010).

5. Jorge Panesi $(1999,2000)$ ha analizado en detalle cómo, según una curiosa torsión irónica, y en el momento mismo de su lanzamiento, esta nueva historia crítica de la literatura argentina, al mismo tiempo que se presentaba impulsando una concepción renovadora y original de la historia literaria (acento puesto en los movimientos internos de la "serie literaria"; mirada atenta a su "autonomía relativa" y a la idea de temporalidades diferenciadas; privilegio de la diversidad de enfoques y puntos de vista por sobre la construcción de un "gran relato" unificador), parecía sin embargo necesitar "ajustar cuentas" a la Viñas (esto es, de manera polémica, excesiva, y a través de un demoledor duelo "cuerpo a cuerpo" entre el crítico y su objeto) con el autor de Literatura argentina y realidad política, en el polémico ensayo de su discípulo Julio Schvartzman "David Viñas : la crítica como epopeya" (1999), lo que no sería sino un síntoma, entre otros, de hasta qué punto las ideas de Viñas continuarían operando, de manera no del todo reconocida, en este proyecto historiográfico.

6. Cada número de La Biblioteca, relanzada en 2004, presenta un tema en torno al cual giran todas las contribuciones. Se advierte en la selección de estos núcleos temáticos una voluntad por propiciar una intervención activa en la contemporaneidad, de manera elocuente en el número 11 
(primavera 2011) cuyo eje es El presente como historia 2001-2011, pero no menos en otros de los ejes propuestos : ¿ Existe la filosofía argentina? (nº 2-3, 2005) ; La crítica literaria en Argentina (n⿳o 4-5, 2006) ; Bitácora de un país (no 9-10, 2010), por mencionar solo algunos. Esta organización temática, los temas elegidos, e incluso su formulación como interrogante en algunos casos, nos remite a la revista de los noventa El ojo mocho, en la que Horacio González jugó un papel central. Los primeros cinco números de esta revista tuvieron los siguientes ejes temáticos : 1. ¿ Fracasaron las ciencias sociales? (1991) ; 2. ¿ Se acabó la crítica cultural ? (1992) ; 3. ¿ Qué significa discutir ? (1993) ; 4. ¿Se puede salvar la teoría? (1994) ; 5 . ¿ A qué llamamos política ? (1994).

7. "En cualquier caso, me gustan los gestos (tan escasos, sin duda incluso imposibles, en todo caso no programables) que ligan dentro de sí lo hiperactual con los anacrónico [...]. Trato de no olvidar que las aproximaciones intempestivas de lo que se denomina la actualidad son a menudo las que más 'se ocupan' del presente" (Derrida 1994). Tomo la cita de Derrida del artículo "Beatriz Sarlo/Horacio González : perspectivas de la crítica cultural”, en el que Judith Podlubne (1998), desde una perspectiva acorde con la que procuro desarrollar en este trabajo, establece un contrapunto entre los "estilos de intervención" de Sarlo y González. Según Podlubne, Sarlo hace de la sincronía con el presente el criterio de validez de su intervención crítica ("La pregunta acerca de qué significa discutir se reformula en Sarlo -por referencia a un presente que se erige como última razón, como explicación definitiva- en qué significa hoy (aquí y ahora) discutir, y es este gesto que cronologiza la cuestión el que debilita su potencia crítica") ; mientras González practica una crítica cultural que "no aspir[a] a guardar con su época una cómoda relación de adecuación", y que se piensa siempre a sí misma y a su lenguaje como objeto de reflexión.

8. La colección ha continuado reeditando otras revistas culturales de los años sesenta-setenta : en 2014 se publicó una edición facsimilar de Pasado y Presente (1963-1965 y 1973), la revista de los gramscianos argentinos agrupados en torno a Oscar del Barco.

9. La reedición de Viñas por Santiago Arcos no solo revela su carácter programático en lo que decide reeditar (sus ensayos críticos) sino también en lo que decide no reeditar (la extensa obra narrativa de Viñas). Sin dudas es posible leer allí una toma de posición editorial respecto a qué sector de la obra de Viñas interpela hoy a nuestro presente con mayor intensidad.

\section{RESÚMENES}

Este trabajo se propone caracterizar algunas de las políticas de reedición y de relectura del pasado reciente en la literatura y la crítica argentina contemporánea. En este sentido, a partir del análisis de una serie de reseñas críticas y de la antología de poesía de los noventa La tendencia materialista, editada por Kesselman, Mazzoni y Selci, se definen los presupuestos teóricos de una concepción lineal de la evolución literaria, que entiende que "lo nuevo" de la literatura está dado por la representación inmediata de las transformaciones actuales en el terreno sociopolítico, porque entiende que la conciencia literaria del presente puede y debe estar en sincronía con su "realidad". A dicha concepción de la relación entre literatura, sociedad y tiempo presente se le contrapone otra (intempestiva, anacrónica) que promueve las relecturas y las reediciones de algunas revistas (Contorno, Literal, Los Libros) y de algunos autores clave de los años sesenta y setenta como una forma de intervención activa sobre el presente. Como ejemplo de esta línea se analizan con mayor detalle las reediciones recientes de la obra de David Viñas. 
Ce travail vise à caractériser certaines politiques de la réédition et de la relecture du passé récent dans la littérature et dans la critique argentine contemporaines. En ce sens, à partir de l'analyse d'une série de recensions critiques et de l'anthologie de poésie des années quatre-vingt La tendencia materialista, éditée par Kesselman, Mazzoni et Selci, nous essayons de mettre au clair les hypothèses théoriques d'une conception linéaire de l'évolution littéraire. Selon cette conception, le «nouveau ", en littérature, est caractérisé par la représentation immédiate des changements actuels dans le domaine socio-politique, car elle suppose que la pleine conscience littéraire peut et doit être en synchronie avec sa "réalité ». Cette conception de la relation entre littérature, société et temps présent s'oppose à une autre (inactuelle, anachronique) qui favorise les relectures et les rééditions de certains revues (Contorno, Literal, Los Libros) et de certains auteurs clés des années soixante et soixante-dix, relecture et rééditions qui constituent une intervention active sur le présent. Comme exemple de cette tendance, ce travail propose de discuter plus en détail les rééditions récentes de l'œuvre de David Viñas.

This work aims to characterize some of the politics of reedition and rereading of the recent past in contemporary Argentine literature and criticism. Starting with the analysis of a series of critical reviews and the anthology of poetry of the nineties La tendencia materialista, edited by Kesselman, Mazzoni and Selci, the article discloses the theoretical assumptions of a linear conception of literary evolution. According to this conception, "the new" in literature is given by the immediate representation of current changes in the socio-political field, since it is assumed that literary consciousness can and should be in synchrony with its "reality". To this conception of the relationship between literature, society, and present time can be opposed another one (an untimely and anachronistic conception) that promotes re-readings and reissues of literary magazines (Contorno, Literal, Los Libros) and key authors of the sixties and seventies as an active intervention on its present. As an example of this tendency, the recent editions of the work of David Viñas are discussed in more detail.

\section{ÍNDICE}

Mots-clés: politiques de la réédition, relecture, critique, passé récent, David Viñas

Keywords: politics of reedition, rereading, criticism, recent past

Palabras claves: políticas de reedición, relectura, crítica, pasado reciente

\section{AUTOR \\ DIEGO PELLER}

Universidad de Buenos Aires 